\title{
PROTECTION OF EXPOSED REBAR LAPS AT CONSTRUCTION SITES
}

\author{
Joo Aik Chan and Abdul Muhaimin \\ Faculty of Engineering and the Built Environment \\ SEGi University \\ Corresponding email: jachan@segi.edu.my
}

\begin{abstract}
Most contractors leave the rebar laps exposed to the environment without any protection in on-site construction. Corrosion damage of the rebar is a serious problem that needs to be addressed, as it is a major problem that affects the characteristics of the reinforced concrete structures. In this research paper attention is drawn on the environmental corrosion of the rebar laps, how the exposure to the environment influences the rebar laps, and ways of protecting it from corrosion. Moreover this research is based to find out how the plastic dip method can help in the protection of the rebar laps. And also to see how this method differs from other methods, and why this method can be a possible solution to the problem. The research was done through some experimentation and the results were evaluated by visual observation. The research has brought a conclusion that the protection of exposed rebar laps at construction sites with the plastic dip paint is in fact a user friendly and economical solution for the problem.
\end{abstract}

Keywords:Corrosion; Rebar laps; Plastic dip paint; User friendly; Economical; visual observation.

\section{Introduction}

Corrosion of reinforcing steel is a major issue in the construction industry. One of the most essential issues that need to be taken into account here is that the corrosion of the reinforcement bar will affect various mechanical properties of the reinforced concrete. Amongst them, the stress transfer or bond action between the reinforcement bars and concrete will be remarkable. The tensile strength of concrete is typically only about $8 \%-15 \%$ of its compressive strength (MacGregor, 1992). Hence, in design the tensile strength of concrete 
is ignored and the reinforcement is needed to overcome the internal forces and moment. The tensile and compressive forces are passed on to reinforcement through bond action. Corrosion being a process which affects the bond strength of the steel and concrete, actions must be taken in order to minimize the effect of it.

In on-site constructions, the limit of casting concrete for columns is maximum $3 \mathrm{~m}$ per time. Therefore for buildings higher than this, the connecting laps remains uncovered for a while, and due to many other reasons the casting may not be continued and the rebar laps remain exposed to the surrounding environment at the construction sites. This assists the rebar laps to corrode; hence the bond strength of the rebar laps is reduced for the subsequent concrete casted.

As it has been previously mentioned, the prevention of corrosion of reinforcement bar is essential as it is associated with the safety of civil engineering buildings and structures. Moreover, finding easier and cost effective ways to protect the rebar laps in on-site construction is highly needed.

\section{Methodology}

For the ease of handling, specimens of $150 \mathrm{~mm} \times 150 \mathrm{~mm} \times 300 \mathrm{~mm}$ concrete columns were made, which means the weight of the samples were roughly $16.2 \mathrm{~kg}$ each.

The steel bars being one of the major influential constituent of the research, T12 steel bars were used as the main reinforcement and for the links it was used R6 bars. The T12 bars were twice the length of the sample specimens so half the length of the bars protruding from the specimen, since the spraying of the paints is done on these bars. The R6 had no major function other than holding the main reinforcement in position while the casting was being done.

The experiments were based on to find out the effectiveness of different spray paints in protecting the rebar laps from environmental corrosion. The paints used were a gloss protective enamel spray, galvanizing spray, cement slurry and the plastic dip paint. 

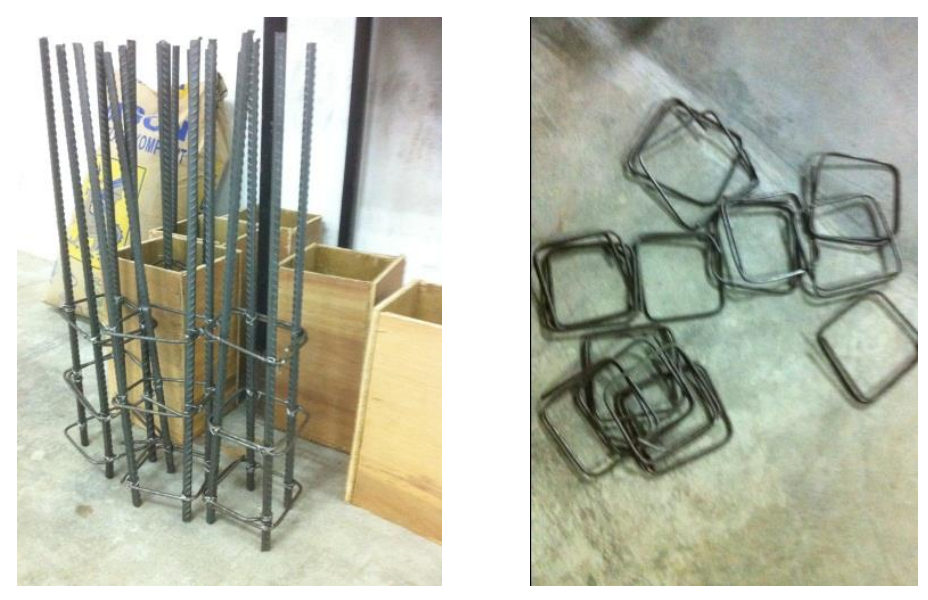

Figure 1. Steel reinforcement

Gloss protective enamel is a spray which is used on metal surfaces to stop rusting on it. This enamel spray creates a glossy finish on the surface. This spray dries in approximately 4 hours and is a durable paint which helps prevent rusting.

Cold galvanising spray is also a spray used on the metal surfaces for corrosion protection. This sprays stops creeping rust and is fast drying. Moreover it is easy to apply and can be used as a top coat primer. It is compatible with most paint finishes and contains no CFC or lead.

Plastic dip paint is also used as a protection of the metal surfaces from corrosion. For this research this was the main item of interest. The whole research was based on identifying the effectiveness of this paint on the corrosion protection of the rebar laps. Even though this paint is used for car parts, machines and tools, the application of this paint on the rebar for its protection from the corrosion was tested in this research.

The cement slurry is just a mixture of cement and water. This is used conventionally and until today it is used as a protection method for exposed rebar laps at construction sites. About half the amount of water for the cement used was mixed to form the slurry used for this experiments. For the experiments $223.6 \mathrm{~g}$ of cement slurry was used.

The experimental procedure for this research involved mainly of three steps. The experiments were done at SEGi University, and hence, 
using some materials and equipment provided by the University. The experimental procedure for the research was as follows;

i. Preparation of Specimens / Casting of Specimens,

ii. Spraying the paints and,

iii. Taking photos / Experimental testing

Some factors such as preparation of moulds, preparation of the reinforcement cage, time required for the specimens to set and removal of the formwork had to be well-thought-out for instance. The casting of specimen, leaving them to set and removing the specimens from the moulds were done at SEGi University.

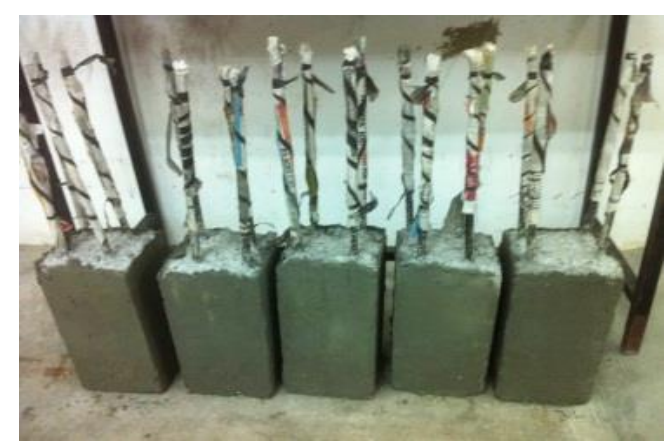

Figure 2. Preparation of Specimens

Each sample was sprayed with a different paint on the third day of casting. The spraying was done according to the instructions given on the label of the spray bottles.

1. Cement slurry;

- Clean the surface from grease and dust and make sure it is dry

- Use a brush to apply the cement slurry on the surface.

- Apply 3 coats of cement slurry in every 5 minutes when the previous coat is a bit dried

2. Gloss protective enamel and galvanizing spray;

- First clean the surface well and let it dry. 
- Shake the can vigorously for two minutes.

- Hold the can upright and spray in a back and forth direction, slightly overlapping each stroke.

- Keep the can the same distance from the surface and in motion while spraying.

- Apply 2 light coats in 3 minutes apart and then another coat 15 minutes later.

3. Plastic dip paint;

- Clean and dry the dust, dirt, rust and others on spraying surfaces.

- Repeatedly shake this product for 1 to 2 minutes, shake the inside contents.

- Press the nozzle, spray evenly back and forth at a distance of 15 to $25 \mathrm{~cm}$ from surface.

- Spray 6 to 8 layers in every 3 minutes for the best results.

Visual observations are the only testing involved for the research. It consisted of taking photos and spotting the difference in the surfaces of the bars for a proper comparison of the changes involved in the observation period of the experiments.

The observation period of the experiments was 28 days. This is the time required the concrete to gain its most of the compressive strength and therefore cast the subsequent part of the structure. Photos were taken at different time intervals within these 28 days, which resembles the normal construction procedures.

For the comparison of the effect of exposure to the environment on the five samples, the control, sample with plastic dip spray, sample with protective enamel, sample with galvanizing spray and the sample with cement slurry, photos were taken on the third, seventh and twenty-eighth day of spraying on the samples.

\section{Results And Discussion}

Analysis of cost effectiveness of different sprays was considered first. It should be noted in the first table shown, the price for each spray bottle is for the net weight of the bottle and the price for cement is for 
the whole bag of $50 \mathrm{~kg}$, and hence these prices are considered as the

\begin{tabular}{|c|c|c|c|}
\hline & \multicolumn{3}{|c|}{ Amount of the spray used (g) } \\
\hline $\begin{array}{l}\text { Type of spray paint } \\
\text { (protection method) }\end{array}$ & $\begin{array}{c}\text { Initial } \\
\text { weight (g) }\end{array}$ & $\begin{array}{c}\text { Final } \\
\text { weight } \\
\text { (g) }\end{array}$ & $\begin{array}{l}\text { Amount } \\
\text { used (g) }\end{array}$ \\
\hline Control (No Paint) & 0.00 & 0.00 & 0.00 \\
\hline \multicolumn{4}{|l|}{ Paint } \\
\hline Galvanizing Paint & 514.56 & & 45.50 \\
\hline Cement Slurry & 50,000 & & 18.00 \\
\hline Plastic Dip Paint & 430.43 & & 19.90 \\
\hline
\end{tabular}

raw prices of the protection methods used.

Table 1. Raw prices of the protection methods that were used for the experimental testing.

Here, it should also be noted from the Table 2, the amount of spray used was depended on the instructions given on the label of the spray bottle. The surface area to which each spray applied was equal. 


\begin{tabular}{|c|c|c|c|c|}
\hline \multicolumn{2}{|c|}{ Protective Enamel Paint } & 423.15 & 368.65 & 54.50 \\
\hline \multicolumn{2}{|c|}{ Galvanizing Paint } & 514.56 & 465.73 & 48.80 \\
\hline Cement Slurry & 223.60 & \multicolumn{2}{|c|}{78.26} & 145.30 \\
\hline $\begin{array}{c}\text { Plastic Dip } \\
\text { Paint }\end{array}$ & 430.43 & 206.83 & 223.60 \\
\hline
\end{tabular}

Table 2. Amount of spray used.

\begin{tabular}{|c|c|c|c|}
\hline Type of paint & $\begin{array}{c}\text { Amount } \\
\text { used(g) }\end{array}$ & $\begin{array}{c}\text { Price (RM) / } \\
\mathbf{g ~ x \mathbf { 1 0 } ^ { 2 }}\end{array}$ & $\begin{array}{c}\text { Surface } \\
\text { area }\end{array}$ \\
\hline $\begin{array}{c}\text { Control (no } \\
\text { paint) }\end{array}$ & 0 & 0 & $0.0115 \mathrm{~m}^{2}$ \\
\hline $\begin{array}{c}\text { Protective } \\
\text { enamel paint }\end{array}$ & 54.5 & 10.8 & $0.0115 \mathrm{~m}^{2}$ \\
\hline $\begin{array}{c}\text { Galvanizing } \\
\text { paint }\end{array}$ & 48.8 & 8.88 & $0.0115 \mathrm{~m}^{2}$ \\
\hline Cement slurry & 145.3 & 0.36 & $0.0115 \mathrm{~m}^{2}$ \\
\hline Plastic dip paint & 223.6 & 4.62 & $0.0115 \mathrm{~m}^{2}$ \\
\hline
\end{tabular}

Table 3. Price per Gram per surface area.

From the results obtained in the Table 3, a bar graph was plotted for the price per gram per surface area for each spray paint as shown below. 


\section{Cost (RM) / g / surface area}

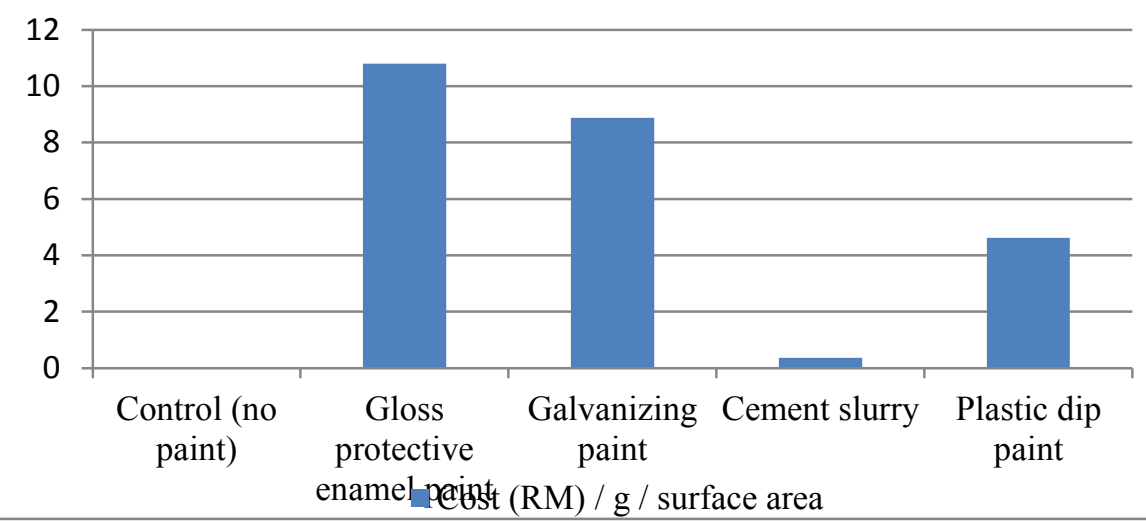

Figure 3. Comparison Between Prices

Secondly the user friendliness of the spray paints was considered. The user friendliness of the methods used for protecting the rebar laps for the experiments was determined in terms of the ease of application and the ease at which it could be removed.

Figure 4 below shows the removability of the plastic dip paint. It should be noted that the plastic dip is a paint which, when harden on the metal surfaces, it gives a rubber covering and hence, it could be easily removed even with the bare hands as shown in the figure.
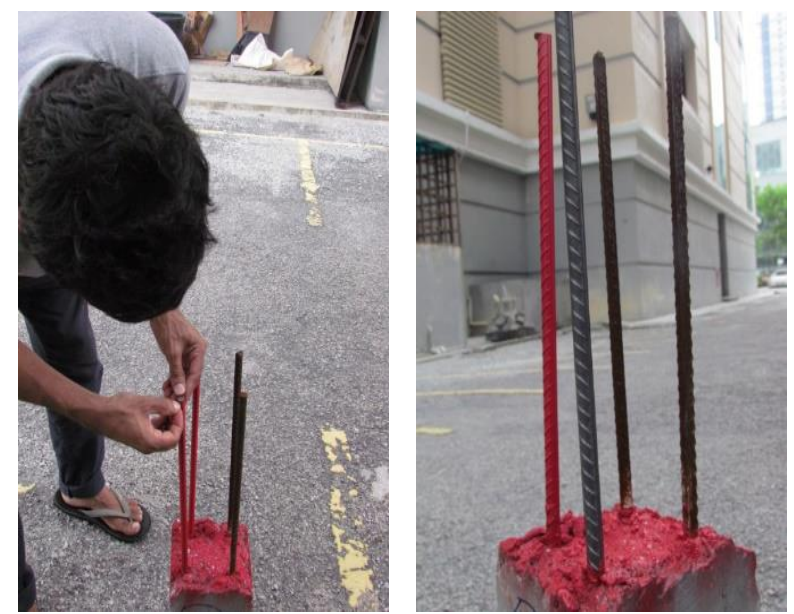

Figure 4. The Removability of Plastic Dip Paint 
In order to understand the user friendliness of each protection method in an effective way, a graph was plotted. However, before plotting the graph a scaling for the user friendliness was required. Therefore scales of zero to five were provided for the ease of application, and scales of zero to five were given for the removability of the paint. For which the ease of application and removability increases as the number increase.

Scaling: $5=$ very easy to remove, $0=$ very hard to remove.

$5=$ very easy to apply or spray, $0=$ very difficult to apply.

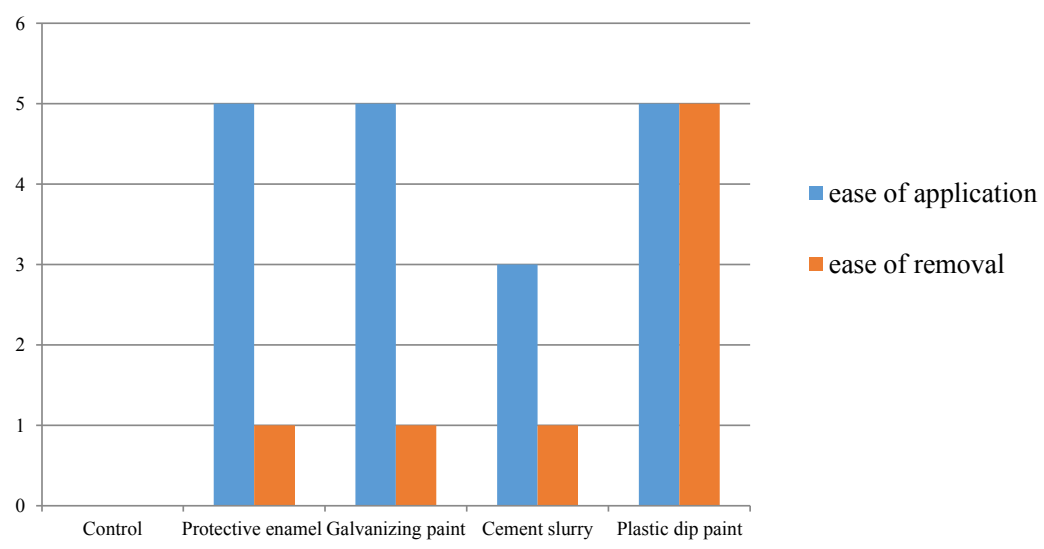

Figure 5. The user-friendliness of different protection methods.

Figure 6 shows the five specimens used for the experimental testing before application of the paints. As clearly seen, the bars were clean and rust free at the beginning. 


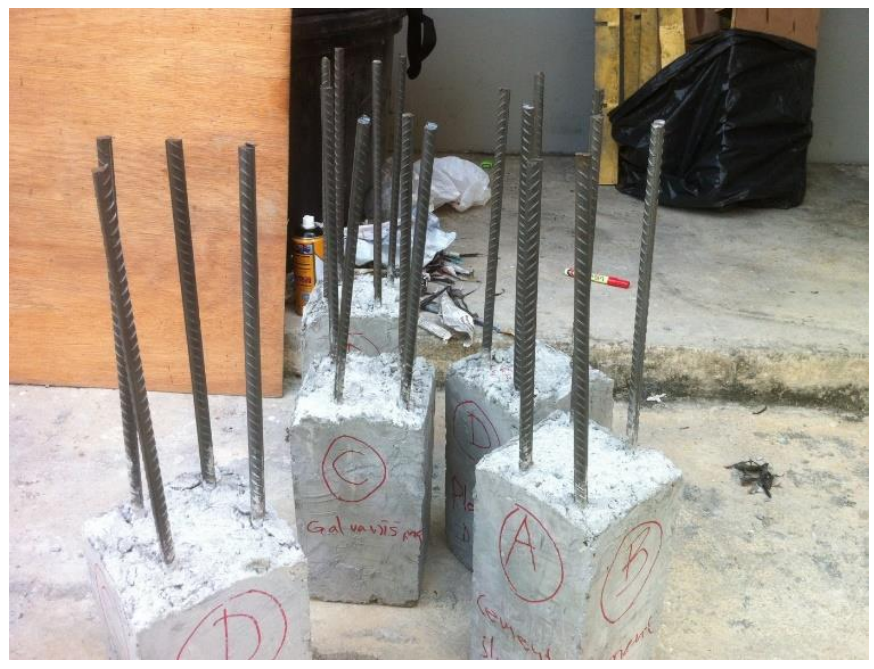

Figure 6. Specimens before paint was applied

The photos taken for the control specimen on day zero, day three, day seven and day twenty eight was arranged in order that the transformation could be observed easily. From the Figure 7, it is observed that the control specimen goes on increasing the state of corrosion as it was expected.
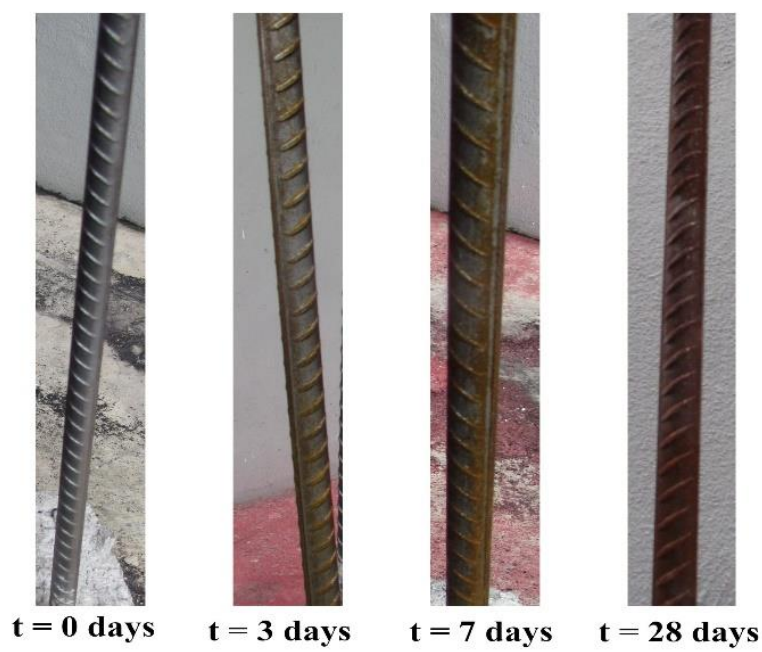

Figure 7. Rusting on the Control Specimens During the Experimental Period. 
The photos that were taken on the third day was analysed for individual specimen in order to understand the efficiency of the paints on the protection of corrosion in this period of the experiments. It was observed from the photos that there was no significant sign of rusting on any of the specimens except for the control specimen. However, there was a bit of rusting observed on one of the bars of the sample with the cement slurry.

It was also observed that there was not a single pitch of rust on the surface of the bar, with the plastic dip paint; on the time the paint was removed on day three.

Figure 8 below shows the state of rust observed on each sample on day three of the experiment. The right-most photo shows the specimen with plastic dip with paint removed from one bar.
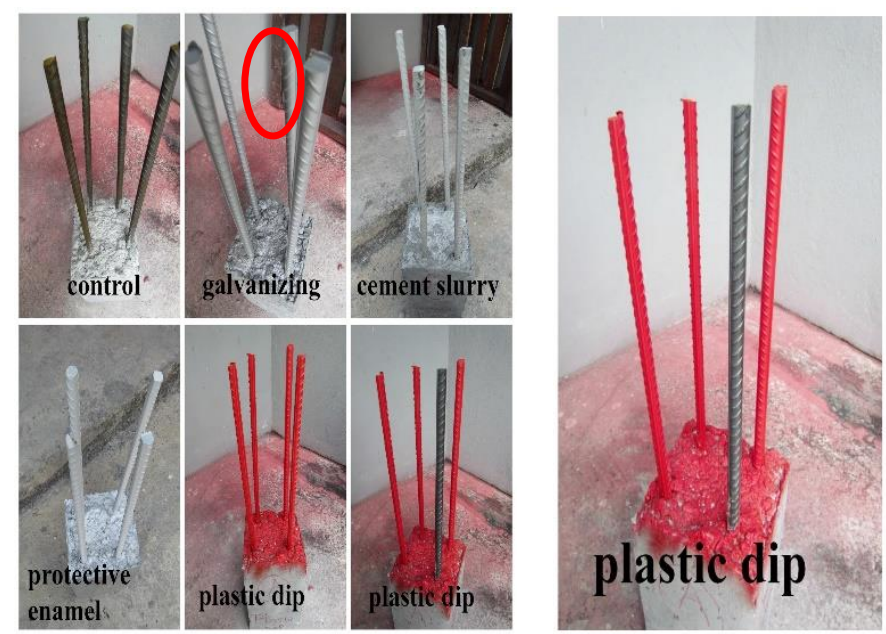

Figure 8. Results for All Specimens on Day 3

Likewise, the states of corrosion of the specimens were observed for day seven, which were still exposed outside in the normal Malaysian environmental conditions. It was observed from the photos that there were signs of rust on each specimen except for the plastic dip.

The control specimen has shown a heavier coat of rust. It should be noted that from the photo below right, which is Figure 9, the bar with 
rust was the bar from which paint was removed on the third day and the bar with no stain of rust is the newly removed bar.
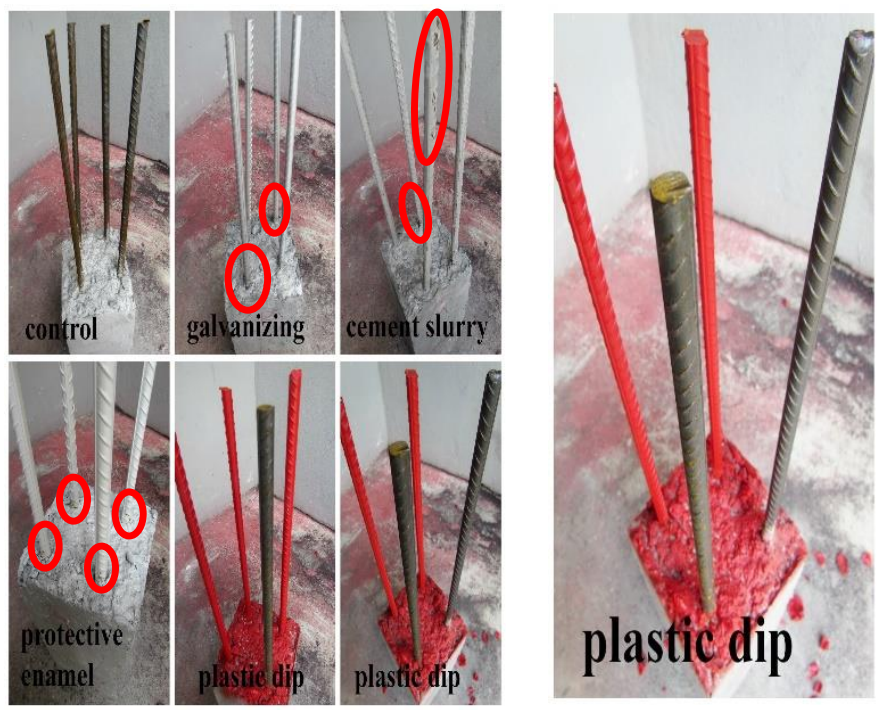

Figure 9. Results for All Specimens on Day 7

Once again, the photos were taken for the last time on day twenty eight for the visual observation and comparison, and therefore the photos were used to analyze the state of corrosion on each specimen for the twenty eighth day of experimental testing or observation.

To follow the same procedure as to the other two days of observation, paint was removed as there was no sign of rust on the outside of the paint observed on plastic dip paint, and it was again observed that there was no stain of rust on the inside of the surface of the bar. However, all other samples have shown an increased state of rusting. 

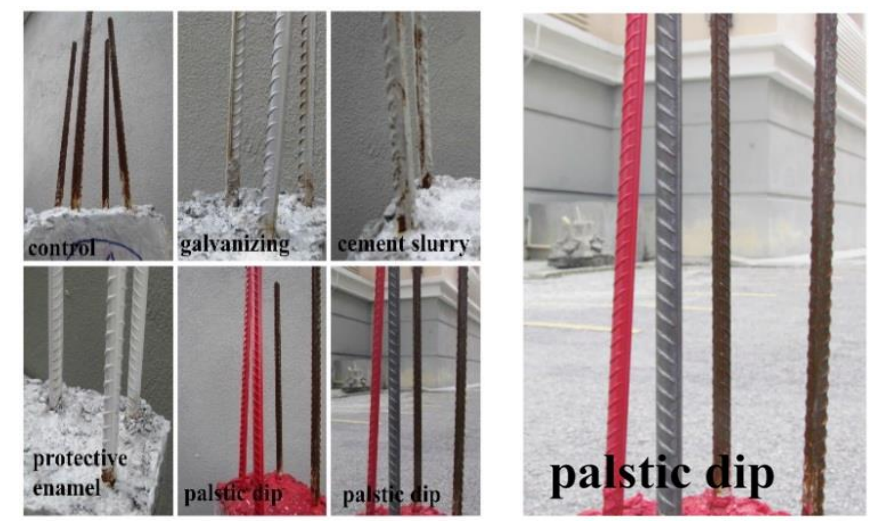

Figure 10. Results for All Specimens on Day 28

The Figure 11 shows the specimen with the plastic dip paint at the different observation days; here it was observed as mentioned previously, the plastic dip paint gives an efficient protection for the rebar. Here it should be noted that the bar with rusting on it for day seven and day twenty eight was the bar from which paint was removed on the third day. The bar with no rusting was with paint removed on the day of observation.
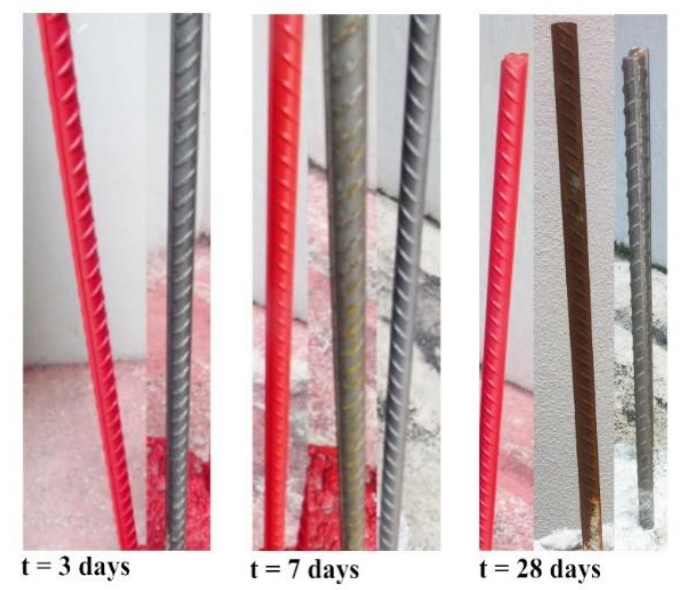

Figure 11. Specimens with Plastic Dip Paint at Different Time Intervals. 
From the final results obtained, which were the photos taken at the day twenty eight of the observation, a comparison was made for each protection method used, and hence concluding the efficiency of the protection methods in terms of prevention of rust in twenty eight days. The comparison was made by the help of the following figure.

From Figure 12 below it is clearly observed that the plastic dip paint was the most efficient way to protect the rebar laps from corrosion as all other specimen shows rusting on it while the plastic dip shows its effectiveness in corrosion protection in this period.
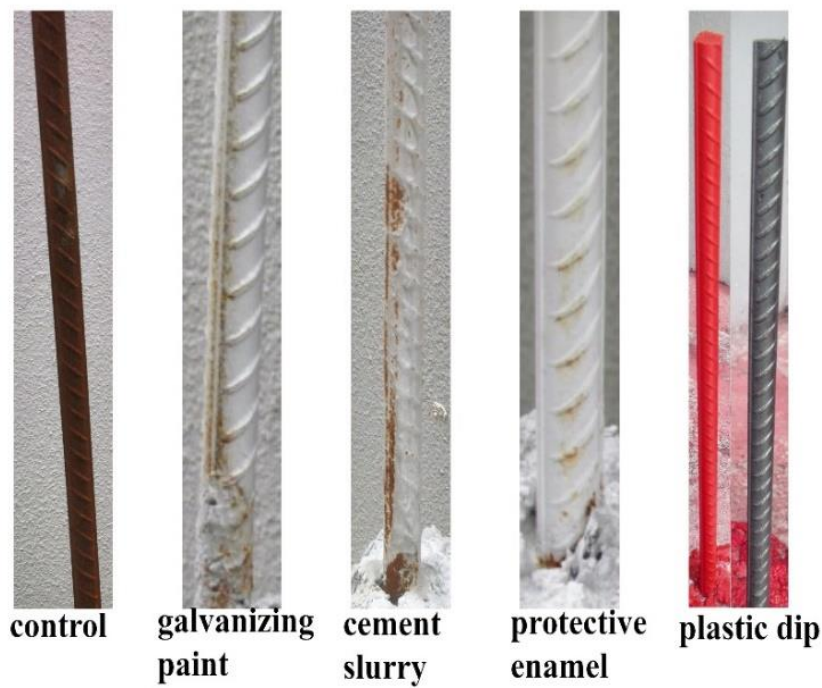

enamel

Figure 12: Final Observation Results for All Specimens.

\section{Conclusion And Recommendations}

The effect of environmental corrosion of the rebar laps was studied in this research through visual observations, in order to determine the effectiveness of different protection methods on the rebar laps in terms of corrosion efficiency in protection, by analysing how well it has managed to protect the bars from rusting throughout the experimental period. The effectiveness of protection methods were was also analysed in terms cost and user friendliness. For this 
research, the conclusions were derived based on the results and observations that were discussed in Chapter 4:

i. Cost effectiveness

Gloss protective enamel had the highest cost amongst the four methods used.

Cement slurry was the cheapest method of protection among these methods.

The plastic dip painting may not be cheaper than the cement slurry; however it outweighs the effectiveness of the cement slurry method in terms of efficiency and user friendliness.

ii. User friendliness

None of the paints used was easy to remove once dried on the surface of the rebar, except for the plastic dip.

Easy removability of the plastic dip paint has shown its user friendliness in the usage of this paint.

iii. Efficiency

Results showed that all paintings offered a significant protection against atmospheric corrosion, especially the plastic dip paint.

After removing of paint from the bar with the plastic dip paint showed its efficiency in protecting the rebar from environmental corrosion.

iv. Visual observations of the bars showed that the bars coated with the galvanizing paint and the normal protective enamel show a pitting corrosion over the base of the bars. This may be due to the lacking of the paint in the area.

v. The plastic dip paint has shown its efficiency in all the aspects that the research has covered; hence it is important to derive or understand why this paint is so effective in corrosion prevention in metals. It may be because as previously mentioned in the literature review; this paint displays a rubber coat of a protective film which sticks on the surface covering the entire surface and protecting it from the environmental factors. 


\section{References}

Aikka The Paints Master - More Colors, More Choices. 2014. Aikka The Paints Master - More Colors, More Choices. [ONLINE] Available at:http://www.aikka.com.my. [Accessed 03 July 2014]

American Galvanizers Association 6881 South Holly Circle, Suite 108 Centennial, CO 80112 USA. 2014. Hot-Dip Galvanizing for Corrosion Protection: A Guide to Specifying and Inspecting HotDip Galvanized Reinforcing Steel. [ONLINE] Available at: http://www.galvanizedrebar.com/Documents/Publication/Specifier s\%20Guide\%20To\%20Rebar\%200504.pdf. [Accessed 02 July $14]$.

Aikka Plastic Dip (Peelable Paint) - Aksesori \& suku cadang mobil dijual Jawa Timur - Surabaya - berniaga.com 2014 [ONLINE] Available at:

http://www.berniaga.com/Aikka+Plastic+Dip+Peelable+Paint+18331124.htm. [Accessed 10 July 2014].

C. Andrade, J. D. Holst, U. Nurnberger, J. D. Whitley, and N. Woodmann. Coating Protection for Reinforcement: State of the Art Report - Google Books. 1995. [ONLINE] Available at: http://books.google.com.my/books?hl=en\&lr=\&id=vQZbYnT_ ncwC\&oi $=$ fnd\&pg=PA1\&dq=protection + of + exposed + rebar + lap +

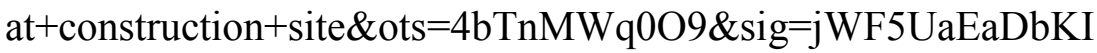
AVGwespHt6EugH0\#v $=$ onepage\&q\&f $=$ false. [Accessed 01 July 2014].

Concrete Reinforcement Corrosion: From Assessment to Repair Decisions - Peter Pullar-Strecker. [ONLINE] Available at: http://books.google.com.my/books?hl=en\&lr=\&id=X2okF77lt AEC\&oi $=$ fnd\&pg $=$ PA1\&dq $=$ protection + of + exposed + rebar + lap $+\mathrm{a}$

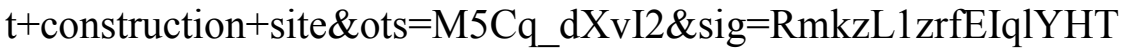

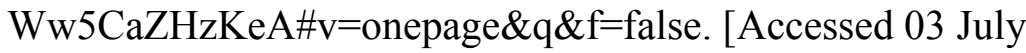
2014].

Dr. Jayanta Saha. 2014. Cost Effective Ways to Protection Steel Structures from Environments. [ONLINE] Available 
at: http://www.steel-

insdag.org/Documents/Corrosion_Protection.pdf. [Accessed 01 July 14].

E. Dafloua , E. Rakantab , G. Batisc. 2014. CORROSION PROTECTION METHODS OF STRUCTURAL STEEL AGAINST ATMOSPHERIC CORROSION. [ONLINE] Available at:

http://www.cortecvci.com/Publications/Papers/VpCIPolymerAddi tives/DAFLOU\%20BATIS\%20VpCI\%20_2_.pdf. [Accessed 02 July 14].

Epoxy Coatings - Sherwin-Williams Protective \& Marine Coatings. 2014. [ONLINE] Available at:_http://protective.sherwinwilliams.com/tools/epoxy-coating-troubleshooting/. [Accessed 10 July 2014].

Jennifer L. Kepler, David Darwin, Carl E. Locke, Jr. 2000. EVALUATION OF CORROSION PROTECTION METHODS FOR REINFORCED CONCRETE HIGHWAY STRUCTURES. [ONLINE] Available at: http://www.iri.ku.edu/publications/SM58.PDF. [Accessed 01 July 14].

J. D. Seddelmeyer P. G. Deshpande H. G. Wheat D. W.Fowler J. O. Jirsa. 2000. Feasibility of Various Coatings for the Protection of Reinforcing Steel—Corrosion and Bond Testing. [ONLINE] Available at: https://www.cc.utexas.edu/research/ctr/pdf_reports/4904_3.pdf. [Accessed 01 July 14]

Laura Alexandra Fuentes, Implementation of Composite Wrapping Systems on Reinforced Concrete Structures Exposed to a Corrosive Laboratory Environment, 1999. [ONLINE] Available at:http://fsel.engr.utexas.edu/publications/docs/Funetes,\%20Laura. pdf. [Accessed 03 July 2014].

S. SYED. 2006. ATMOSPHERIC CORROSION OF MATERIALS. [ONLINE] Available at: http://eclsun.uaeu.ac.ae/ejer/issues/v11/pdf_iss1_11/p1_ATMOSP 
HERIC_CORROSION_OF_MATERIALS.pdf. [Accessed 02 July 14]. 